\title{
Waste Characterization as an Element of Household Waste Management Operations: A Case Study in Limbe, Cameroon
}

\author{
Lawrence Oben Mbeng $^{*}, 1$, Paul S. Phillips ${ }^{2}$ and Roy Fairweather ${ }^{2}$ \\ ${ }^{I}$ The University of Douala, Institute of Fisheries and Aquatic Sciences at Yabassi, P.O. Box 7236, Bassa Douala, \\ Cameroon \\ ${ }^{2}$ School of Science and Technology, Newton Building, Avenue Campus, University of Northampton, Northampton, NN2 \\ $6 J D, U K$
}

\begin{abstract}
The development of sustainable waste management practice in Cameroon requires that waste characterization, composition and arisings, are used as a tool for waste planning and practice for household waste. Therefore to obtain accurate data that will drive improved waste management planning and operations in Limbe - Cameroon- a waste characterization study was undertaken, in a case study area (February and April of 2008), to underpin future strategy and planning. The study took account of seasonality - a vital issue for Cameroon. To take account of societal issues, the study included the high (HIRA), medium (MIRA) and low income residential areas (LIRA), for household waste in the case study area in Limbe. In the study, it was found that waste generation per capita was low for both seasons (dry and wet), HIRA (0.66 kg and $0.76 \mathrm{~kg})$, MIRA $(0.58 \mathrm{~kg}$ and $0.65 \mathrm{~kg})$ and LIRA $(0.53 \mathrm{~kg}$ and $0.60 \mathrm{~kg})$, compared to cities in other developing countries in Africa. It was found that the waste stream was predominantly purtrescible and contained few recyclable materials. This study has demonstrated that the characterization and determination of composition and arisings, of household waste is the first step required for the successful design of sustainable waste management strategy and practice.
\end{abstract}

Keywords: Cameroon, household waste, waste characterization, composting, recycling, reuse.

\section{INTRODUCTION}

\section{Review of Waste Management in Developing Countries}

Household waste management in developing countries is plagued by a number of problems, due to the fact that waste characteristics and composition differ according to source [1], solutions for which are mainly constrained by financial and technological deficiencies [2]. Added to this, are a number of gaps and serious shortages of hard data and statistical information about the situation in the cities of many developing countries. For example, little is known about per capita generation, the total and weekly or mean average from household and non-households (commercial and industrial premises) or its composition by type of generator [3].

According to the African Development Bank findings of October 2000 [4], solid waste management practices in major municipalities in the developing countries including e.g. Cape Town, Cairo, Nairobi and Accra revealed the following: Waste characterization data specific to African cities is generally not available; the composition of the waste varies depending upon such diverse variables as urbanization, commercial enterprises, manufacturing, and service sector activities; solid waste management in most

*Address correspondence to this author at the University of Douala, Institute of Fisheries and Aquatic Sciences at Yabassi, P.O. Box 7236, Bassa Douala, Cameroon; Tel: (+237) 700362 24;

E-mail: obenmbeng@yahoo.co.uk countries is characterized by inefficient collection methods, insufficient coverage of the collection system and improper disposal of municipal solid wastes. Also, no country has specific waste management legislation, although legislation is being initially drafted now in some countries. Integrated waste management is not implemented; very little information is available on composting, controlled sanitary landfills and the recovery of the landfill gas. Of concern is the current lack of regulatory initiatives to manage waste minimization, with the potential for reducing the hazardous waste problem and no differentiation is made in the collection of different types of waste, although some municipalities have implemented higher taxes for commercial waste. Overall, funding for waste management is always inadequate, and real costs are never fully recovered.

Over the years the development of improved waste management practices in the developing countries has been of key importance with Cameroon not an exception. In Cameroon, emphasis has been placed on the improvement of household waste management, via local authorities, with another smaller contribution by the private sector. However, in the absence of qualitative and quantitative data from waste streams, regarding source, per capita generation and physical characteristics, it becomes difficult to develop local solutions promoting sustainable solid waste management in Cameroon. It is for this reason that a waste characterization study was conducted because, according to Defra [5], it can 
provide valuable data to assist with waste management research, planning and operations.

\section{Overview of Cameroon}

Cameroon is located in the Gulf of Guinea between Gabon, Guinea Republic and Nigeria with 15.7 million inhabitants [6]. Waste management in Cameroon is a major environmental problem facing many municipalities and Cameroon [7] like other developing countries is facing high rates of urbanization, estimated at about $4 \%$ annually, compared to an annual population growth of about $2.7 \%$ [8]. This growth is occurring in a period during which the country has been experiencing socio-economic pressures that have led to a decline in economic growth. Since the mid 1980 s the fall in oil prices followed by the National Structural Adjustment Programs of the early nineties have resulted in a serious crisis in financial resources [9]. As a result, the Government considerably reduced its investments and subsidies in the urban sector. Since then, living standards have declined, particularly in the areas of health and education [10]. Of all sectors, household waste management has been one of those most affected. Uncollected, illegally or improperly disposed of household waste poses serious risks to public health and the environment $[11,12]$.

\section{An Overview of Household Waste Collection and Disposal in Limbe}

Limbe is a coastal town and a major economic center of the South-West Region of Cameroon. It has a population of approximately 150,000 inhabitants and a land area of 596 $\mathrm{km}^{2}$ [13]. Limbe has experienced an influx of migrant workers at the National Oil Refinery and the Cameroon Development Co-operation (CDC). $\mathrm{CDC}$ is the biggest employer in Cameroon after the civil service, because of its huge palm, banana and tea plantations. This increase in population has had an impact on household waste generation with a significant increase of 20 tonnes /day in 2000 to 26 tonnes /day in 2006 [14]. However, these are mainly mean values due to seasonal variation.

With increasing volumes of household waste generated in Limbe, coupled with the popular notion that waste management is an activity of collect and dump somewhere else, different types of collection methods have been adopted. But in reality, open dump or low grade landfill is the only disposal method [15].

Pre -collection-This usually involves the movement of household waste by children and women from homes to public skips. The disadvantage of this collection method is that most of the waste is transported in open containers and clandestine dumping is common, where skips are in remote locations.

Door to door collection-This is done by a garbage truck on a fixed route. There are better collection services in the high income residential areas when compared to the medium or low income residential areas. The problems include littering of waste when loading into the collection truck and by wind or domestic animals when put in containers without a lid. There is very low collection efficiency during the rainy season particularly in the low income residential areas with their earth roads.
Fixed point collection-Here skips are placed on selected locations in the city and the type and number determined by the economic wealth of the area. The most common problem is littering by the waste collection crew and waste pickers. The littered and uncollected waste is usually a breeding ground for rats, flies and mosquitoes.

Street sweeping -This is mostly carried out in the high income residential area with tarred roads as well as some commercial areas with outdoor markets and other informal activities. The main problem here is that there are too many street sweepers in the high income residential areas with just a few in the middle income residential areas. There are also not enough waste collection bins at some streets corners as well as difficulties in removing chewing gums on street pavements.

Campaigns for the general public are carried out. The "Clean up campaign" - is a campaign to keep Limbe clean, run under the supervision of the hygiene and sanitation department of the Limbe municipality. Cleaning of surroundings and business premises takes place once each month between 8 am and 12 noon with all government offices, public and private businesses remaining closed. However, exemption levies of $\$ 1$ for taxis and \$2 for the general public encourages non participation. There are also many difficulties in implementing and monitoring the exemption levy and so the campaign is of limited value.

\section{Structure of Waste Management in Cameroon}

In Cameroon, waste management has developed very slowly over the past decade. Several ministerial departments have mandates to implement solid waste management regulations and the highest body responsible for municipal solid waste management is the Inter-Ministerial Commission for Municipal Waste Management (ICMWM), created under the direction of the Prime Minister Decree No. 95/230/PM of $31 / 04 / 95$ [16]. It is charged with formulation and policy development for appropriate municipal solid waste management strategies.

According to the Cameroonian Law on Environmental Management No. 96/12 of 5/ 081996 [16]:

"Waste shall be any residue from the
production, processing or utilization process,
any substance or material produced or, more
generally, any movable and immovable goods
abandoned or intended to be abandoned" and
"Waste management" shall be the collection,
transportation, recycling and elimination of
waste, including the monitoring of disposal
sites."

Despite Government efforts to create and implement legislation related to sustainable waste management, the current policy framework is not efficient. An inadequate legislative framework is a key reason for the lack of effective engagement of industry, commerce and the general public in more sustainable waste management practices [9].

The aim of this paper is to present the results of a waste characterization study carried out in Limbe as a function of socio geo-demographic data. The areas surveyed covered high, medium and low income residential areas, representing 
high (HIRA), medium (MIRA) and low income (LIRA) groups.

\section{MATERIALS AND METHODS}

The study sought to determine baseline composition of household waste taking into account seasonality of environmental conditions. Site visits were made followed by direct observation and visual assessment of the household waste collection, treatment and disposal methods in the HIRA, MIRA and the LIRA's. Prior to the collection and weighing procedure, focus group discussions and interviews were conducted in the English and French languages or Pidgin English. This was to get the opinion of the residents regarding household waste arising, composition and the effectiveness of how it is being managed.

\section{Household Survey}

Households were selected by stratified random technique from three different residential areas in Limbe [15]. Household size (number of people living in the house at the time of the study and making use of the waste bin) was used in this study as a requirement for determining the per-capita waste generation. The sampling matrix [17] for the study was in line with that in monitoring of home composting initiatives in UK (see Table 1).

Households for the study were selected from three residential areas:

- $\quad$ High income residential areas (HIRA) made up of single detached houses outside the city centre with gardens;

- $\quad$ Medium income residential areas (MIRA) made up of high rise buildings or multiple occupancy properties with no gardens and close to shopping centre or the central business district; and

- Low income residential areas (LIRA) made up of illegal and non-permanent structures or houses in unplanned and squatter settlements and occupied by struggling families with very low income.
Of the 43 households contacted in Limbe through focus group discussions, 39 accepted to participate in the survey (response rate was 90.7\%). The 39 households surveyed had 188 persons as indicated in Table 2 . The average family size was 4 persons in the HIRA; 5 persons in the MIRA; and 6 persons in the LIRA. While it was easy to get data on the number of persons per households from questionnaires and interviews in these areas, it was difficult to get the actual populations.

\section{Waste Collection and Weighing Procedure}

Residents in the HIRA, MIRA and LIRA's were provided with 7 pre-weighed plastic bags for the 7 day study and one extra bag in case it became necessary. The weighing was done with a hand scale and the data were recorded in kilograms on data sheets during all weighing operations. A study period of seven days was chosen with the aim of:

- Minimising waste hoarding behaviors that can skew data collection [18];

- $\quad$ Providing daily fluctuations during the week days and week-ends;

- $\quad$ Educating residents of the impacts of pre-selection and source separation on the baseline data.

The researcher and two volunteers visited participating households and weighed the residual waste with a hand scale. The residual waste was then transferred to a sort site and sorted by material category on a $10 \mathrm{~mm}$ screen. The sorting procedure was in line with procedures used in waste characterization studies [19]. Fines with a diameter of less than $10 \mathrm{~mm}$ that filtered through and fell on the floor were collected and weighed.

Based on the fact that the primary aim of the characterization study was, via source separation, for composting and recycling options it was decided that the waste be sorted into high nitrogen organics (fruit peels and other kitchen wastes) and high carbon organics (such as dry leaves and papers). All categories employed are found in Table 3.

Table 1. Sampling Matrix [17]

\begin{tabular}{|c|c|c|}
\hline Socio/Geo - Demographic Factors & $\begin{array}{l}\text { Waste Management Service Delivery } \\
\text { Infrastructure }\end{array}$ & Other Factors \\
\hline $\begin{array}{l}\text { - Average household size. } \\
\text { - Average garden size. } \\
\text { Degree of daily occupancy, e.g. holiday } \\
\text { homes, retirement homes, proportion of } \\
\text { people 'working from home', number of } \\
\text { 'housewives', etc. } \\
\text { - Demographics of occupants (age and } \\
\text { gender), e.g. families with children; } \\
\text { students; retired pensioners, etc. } \\
\text { - Type of home ownership, e.g. owned, } \\
\text { rented, council housing. } \\
\text { Type of property, e.g. detached house, flat, } \\
\text { bungalow, etc. } \\
\text { Local affluence/level of household } \\
\text { deprivation. } \\
\text { Number of residents in full-time } \\
\text { employment. }\end{array}$ & $\begin{array}{l}\text { - } \quad \text { Residual waste bin size. } \\
\text { - } \quad \text { gvailability of kerbside recycling and/or } \\
\text { - } \quad \text { Regularity of collection services. } \\
\text { - } \quad \text { Proximity to Civic Amenity Site. } \\
\text { - } \quad \text { Proximity to Bring Sites. } \\
\text { - } \quad \text { Home composting bin distribution. }\end{array}$ & 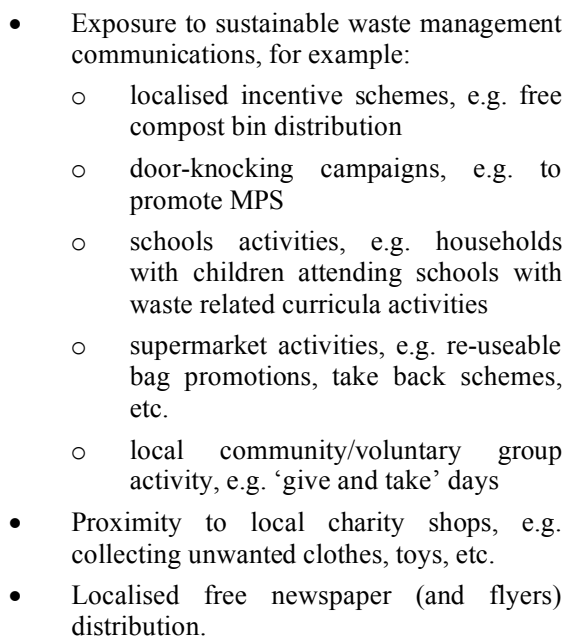 \\
\hline
\end{tabular}


Table 2. Household Survey Data for Limbe

\begin{tabular}{|c|c|c|c|c|}
\hline $\begin{array}{c}\text { Sampled Residential } \\
\text { Areas }\end{array}$ & $\begin{array}{c}\text { No. of Households } \\
\text { Contacted for the Study }\end{array}$ & $\begin{array}{c}\text { No. of Households that } \\
\text { Participated in the Study }\end{array}$ & $\begin{array}{c}\text { No. of Persons that } \\
\text { Participated in the Study }\end{array}$ & Average Family Size \\
\hline \hline $\begin{array}{c}\text { High Income Residential } \\
\text { Area (HIRA) }\end{array}$ & 17 & 13 & 46 & 4 \\
\hline $\begin{array}{c}\text { Medium Income } \\
\text { Residential Area (MIRA) }\end{array}$ & 13 & 13 & 66 & 5 \\
\hline $\begin{array}{c}\text { Low Income Residential } \\
\text { Area (LIRA) }\end{array}$ & 13 & 13 & 76 & 6 \\
\hline Total & 43 & 39 & 188 & \\
\hline
\end{tabular}

\section{RESULTS AND DISCUSSIONS}

\section{Waste Generation}

The mean or weekly average was calculated by averaging the daily totals of waste collected over the 7 day period, while the per capita waste generation was calculated by first averaging the daily weight of waste of each household, then dividing this by the number of residents (see Table 4). The trend in the per capita generation for Limbe, Cameroon was lower than those of some low income countries of $0.64 \mathrm{~kg}$ [20].

\section{Relationship of Waste Generation to Household Size}

Few studies in Cameroon have investigated the relationship of waste generation to household size. Notwithstanding, previous studies in some developing countries have shown that there is a relationship between waste generation and household size [21]. As the number of household occupant's increases, waste generation has been found to decrease per person, mainly because of economies of scale in the consumption of goods and packaging in developing countries [21]. Nevertheless, "Abu- qdais et al. [21] found" a statistically significant but weak negative relationship between waste generation and household size in Abu Dhabi $\left(\mathrm{R}^{2}=0.11\right)$, while "Bolaane et al. [22] found" a similar weak negative relationship in Gabarone, Botswana $\left(\mathrm{R}^{2}=0.34\right)$. However, "Parizeau et al. [18] found" a weak $\left(R^{2}=0.35\right)$, but significant $(p=0.000)$ negative relationship between waste generation and household size.

Results from a waste characterization study in Ilorin, Nigeria [23], revealed that, the number of people living in a house can fluctuate from week to week as relatives move in and out. Based on this, [9] indicated that waste per capita estimates for Siem Reap, Cambodia was not rigorous because the waste characterization study was conducted roughly one month after the household survey was concluded.

In the Limbe study, a bivariate correlation analysis was carried out using Pearson. The aim was to determine the relationship between waste generation and household size based on seasonality in the three residential areas. Pearson correlation for the dry season (February) revealed a

Table 3. Household Waste Composition Profile

\begin{tabular}{|c|c|c|c|c|c|c|c|c|}
\hline Categories & Putrescibles & Plastics & Metals & Papers & Glass & Textiles & Fines & Miscellaneous \\
\hline Sub-categories & $\begin{array}{l}\text { Food remnants, } \\
\text { fresh and } \\
\text { decaying leaves, } \\
\text { vegetation and } \\
\text { other garden } \\
\text { waste }\end{array}$ & $\begin{array}{l}\text { Plastic bottles } \\
\text { and packaging }\end{array}$ & $\begin{array}{l}\text { Cans and bottle } \\
\text { caps, ferrous } \\
\text { metal and } \\
\text { aluminium } \\
\text { items }\end{array}$ & $\begin{array}{c}\text { Newspapers, } \\
\text { magazines, } \\
\text { office papers, } \\
\text { junk mails and } \\
\text { envelopes }\end{array}$ & $\begin{array}{l}\text { Glass bottles } \\
\text { and jars }\end{array}$ & $\begin{array}{l}\text { Clothes and } \\
\text { shoes }\end{array}$ & $\begin{array}{l}\text { Ash, dust and } \\
\text { sand }\end{array}$ & $\begin{array}{l}\text { Wood, stones } \\
\text { and pebbles, } \\
\text { waste electrical } \\
\text { and electronic } \\
\text { equipments and } \\
\text { batteries, used } \\
\text { paints and } \\
\text { solvents }\end{array}$ \\
\hline
\end{tabular}

Table 4. Descriptive Statistics for Waste Generation in February and April

\begin{tabular}{|c|c|c|c|c|c|c|}
\hline \multirow{2}{*}{$\begin{array}{c}\text { Residential } \\
\text { Areas }\end{array}$} & \multicolumn{3}{|c|}{ February (Dry Season) } & \multicolumn{4}{c|}{ April (Wet Season) } \\
\cline { 2 - 7 } & Total Generation & $\begin{array}{c}\text { Mean (Weekly } \\
\text { Average }\end{array}$ & $\begin{array}{c}\text { Per Capita } \\
\text { Generation } \\
\text { Kg/Pers/Day }\end{array}$ & Total Generation & $\begin{array}{c}\text { Mean (Weekly } \\
\text { Average }\end{array}$ & $\begin{array}{c}\text { Per Capita } \\
\text { Generation } \\
\text { Kg/Pers/day }\end{array}$ \\
\hline \hline HIRA & 213.5 & 30.5 & 0.66 & 246 & 35.1 & 0.76 \\
\hline MIRA & 269.5 & 38.5 & 0.58 & 299 & 42.7 & 0.65 \\
\hline LIRA & 282 & 40.3 & 0.53 & 320.5 & 45.8 & 0.60 \\
\hline
\end{tabular}


statistically significant $(\mathrm{P}<0.01)$ but weak, positive relationship $\left(\mathrm{r}=.393 ; \mathrm{R}^{2}=.015\right)$ for HIRA and a statistically non significant $(\mathrm{P}>0.01)$ for MIRA with a weak, positive relationship $\left(r=.043 ; \mathrm{R}^{2}=0.0019\right)$ between waste generation and household size. This was the same for LIRA $(\mathrm{P}>0.01)$ but with a weak positive relationship $\left(r=.362 ; R^{2}=0.13\right)$ (See Fig. 1 and Table 5).

The wet season (April) data for Limbe showed a statistically non significant $(\mathrm{P}>0.01)$, but weak positive relationship for HIRA $\left(r=.117 ; \mathrm{R}^{2}=0.014\right)$, strong positive relationship for MIRA $\left(\mathrm{r}=.512 ; \mathrm{R}^{2}=0.26\right)$ and LIRA $(\mathrm{r}=.382$; $\mathrm{R}^{2}=0.15$ ) between waste generation and household size (See Fig. 2 and Table 5).

This study suggests that socio geo-demographic factors are mainly responsible for the decrease in waste generation with household size. The dry season is considered the planting season and in the LIRA, agriculture is the main economic activity. Residents of the LIRA usually leave their homes as early as 5 am to plough the fields and only get home at about $6 \mathrm{pm}$, with less time being spent at home. In

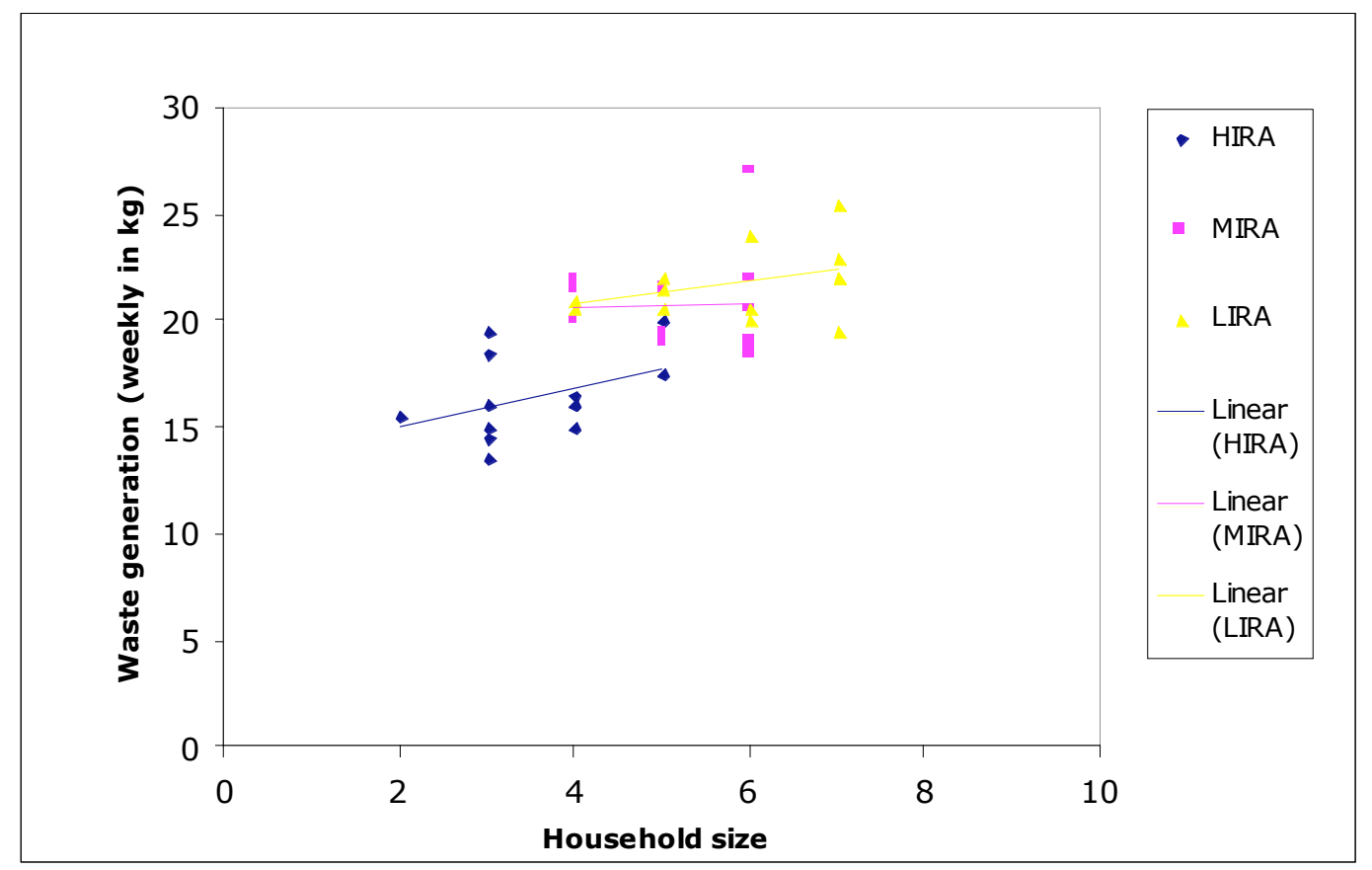

Fig. (1). Scatterplot and regression line of household size against dry season waste generation.

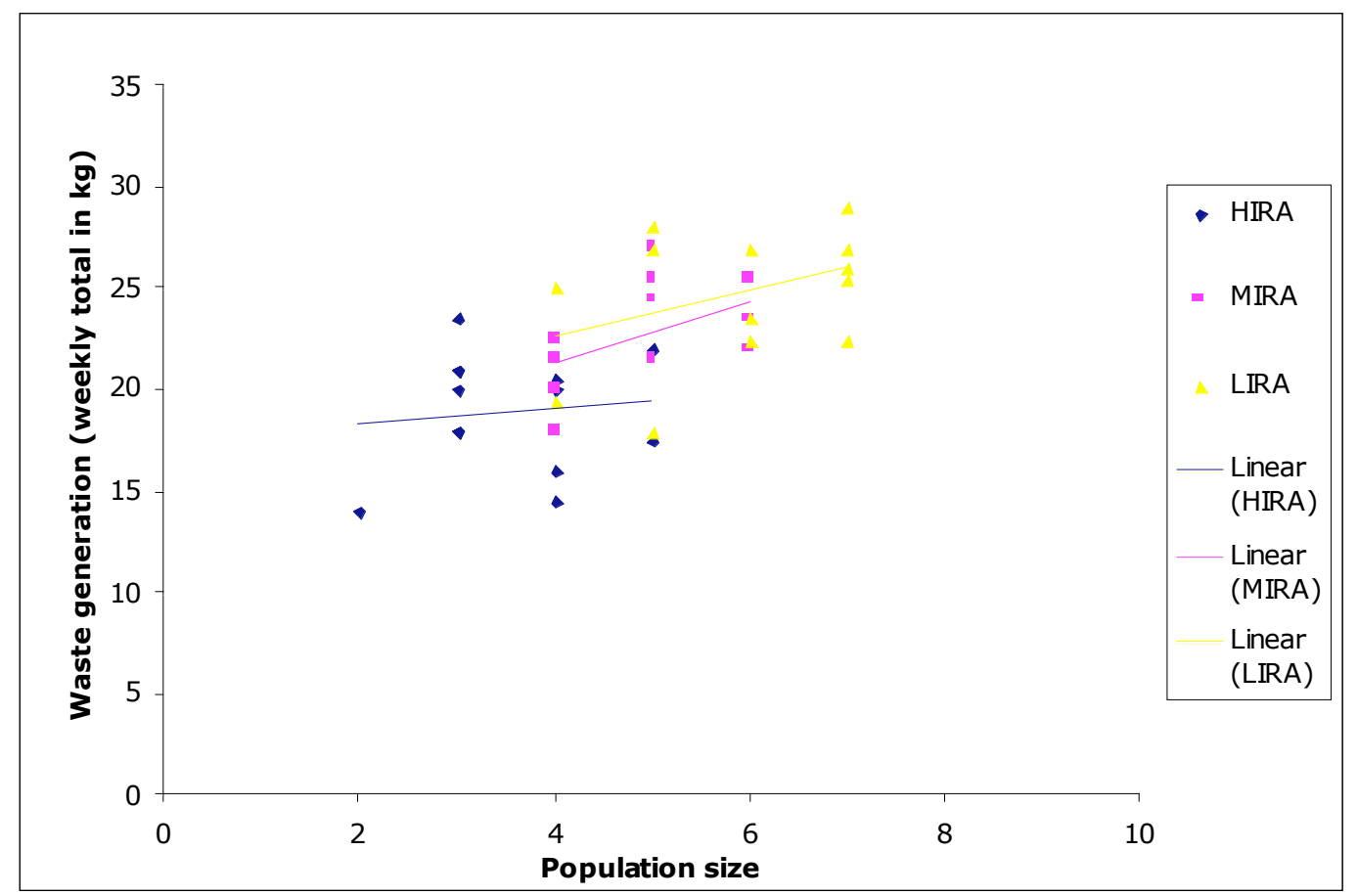

Fig. (2). Scatterplot and regression line of household size against wet season waste generation. 
addition to food crop production in the LIRA, other activities include horticulture and livestock farming. Here the organic fraction of the waste is either used as compost (manure) on agricultural farmlands or as food for domestic animals. Other factors are linked to temporal employment, resulting in people moving from one job to another and spending fewer days at home.

Table 5. Correlations of Waste Generation and Household Size

\begin{tabular}{|c|c|c|}
\hline \multirow{2}{*}{ Residential Area } & \multicolumn{2}{|c|}{ Correlation Coefficient for Limbe } \\
\cline { 2 - 3 } & Dry Season (February) & Wet Season (April) \\
\hline \hline HIRA & $\mathrm{r}=.393, \mathrm{~N}=13, \mathrm{P}<0.01$ & $\mathrm{r}=.117, \mathrm{~N}=13, \mathrm{P}>0.01$ \\
\hline MIRA & $\mathrm{r}=.043, \mathrm{~N}=13, \mathrm{P}>0.01$ & $\mathrm{r}=.512, \mathrm{~N}=13, \mathrm{P}>0.01$ \\
\hline LIRA & $\mathrm{r}=.362, \mathrm{~N}=13, \mathrm{P}>0.01$ & $\mathrm{r}=.382, \mathrm{~N}=13, \mathrm{P}>0.01$ \\
\hline
\end{tabular}

This was not the case with residents in MIRA and HIRA with a positive correlation between waste generation and household size as shown in Fig. (1). From interviews, the results were linked to good income from semi or permanent employment and a high purchasing power of consumer goods. This was the case of the wet season in the MIRA and the HIRA (see Fig. 2). However, this was not the same for LIRA in the wet season as shown in Table 5 and Fig. (2) which revealed a statistically non significant and a weak positive relationship between waste generation and household size.

In the wet season, considered the harvesting season for food crops and vegetables in Cameroon, there is usually plenty of food to eat as well as plenty of waste being generated. The main reason for the throw away attitude in the LIRA stems from the fact that, many households have lower incomes hence unable to buy refrigerators for the preservation of these foodstuffs with the result that the unsold get rotten and become waste. For the MIRA and HIRA, the statistically significant and strong, positive relationship between waste generation and household size is linked to good income and a high purchasing power of consumer goods. The study found out that in some neighborhoods of the HIRA, more than $90 \%$ of the men and women of working age worked with the National Petroleum Company (SONARA). Despite the high income, the average family size was found to be low when compared to the MIRA and the LIRA (see Table 2). Notwithstanding, a positive correlation was found between waste generation and family size.

\section{Relationship of Waste Generation and Composition to Culture and Lifestyles}

The influence of lifestyles and culture on household waste generation and composition is well documented in some developing countries e.g. in Seoul where a significant proportion of the residential waste was charcoal ash up to the 1980s [24]. Household waste in South Korea was also found to have a high moisture content because Koreans eat a lot of kimchi (Korean pickle). This was a contributing factor for the weight increase of the putrescible fraction [24].

The findings of the Limbe study are in line with other studies conducted in Tanzania [25] and Makurdi in Central Nigeria [3] which shows a strong link between lifestyle and waste generation and composition. Culturally, the Bakwerians (indigenes of Limbe) have a long history of pig farming. It is for this reason that household waste from the LIRA did not reflect the household size, as much of the organic fraction in the waste was used as food for pigs. In the MIRA and HIRA the positive correlation between waste generation and composition to culture/lifestyle could be linked to the increase in consumption orientated lifestyles and qualitative change in consumer goods in Cameroon e.g. gift cards and packaging goods particularly during the Easter holiday period. The quantity of waste paper and card, plastics, glass and metal waste recorded in the MIRA and HIRA (see Table 6 and Figs. 3-5) raises the question whether recycling and reuse can be a sustainable option. A recent study [26] reported that some reuse activities have been practiced by the informal sectors in the LIRA. The situation could however be improved if the informal sectors are properly integrated as this will reduce poverty and increase environmental sustainability in the poorest communities of the LIRA.

\section{Waste Management Operations for Limbe}

In Limbe there is no organized program for source reduction, reuse and recycling, hence no value is obtained from household waste. Despite the lack of organizational capacity in municipal waste management and a lack of short-, medium- or long-term planning, small scale composting projects at many part of the city seem likely to be successful. For small scale the start up costs would be very low and Social Enterprises (Third Sector) from local people could be developed to manage them and sell the low grade compost to local markets. Large composting plants are likely to generally unsuccessful due to higher costs. The problem with large scale composting, at the present, is that the market for compost is small due to competition with chemical fertilizers and the decreasing size of farmland around Limbe. The

Table 6. Waste Composition for February and April

\begin{tabular}{|c|c|c|c|c|c|c|c|c|c|c|c|c|c|c|c|c|}
\hline & \multicolumn{16}{|c|}{ Waste Constituents (\%) } \\
\hline & Feb & Apr & Feb & Apr & Feb & Apr & Feb & Apr & Feb & Apr & Feb & Apr & Feb & Apr & Feb & Apr \\
\hline HIRA & 33.9 & 35.9 & 9.4 & 10.7 & 5.4 & 7.4 & 3.3 & 14.8 & 7.7 & 8.8 & 7.7 & 7.4 & 17.1 & 8.2 & 15.2 & 7.0 \\
\hline MIRA & 53.1 & 58.5 & 3.8 & 7.1 & 5.1 & 5.4 & 3.7 & 4.2 & 4.3 & 3.0 & 4.8 & 1.9 & 16.6 & 10.7 & 8.6 & 9.0 \\
\hline
\end{tabular}



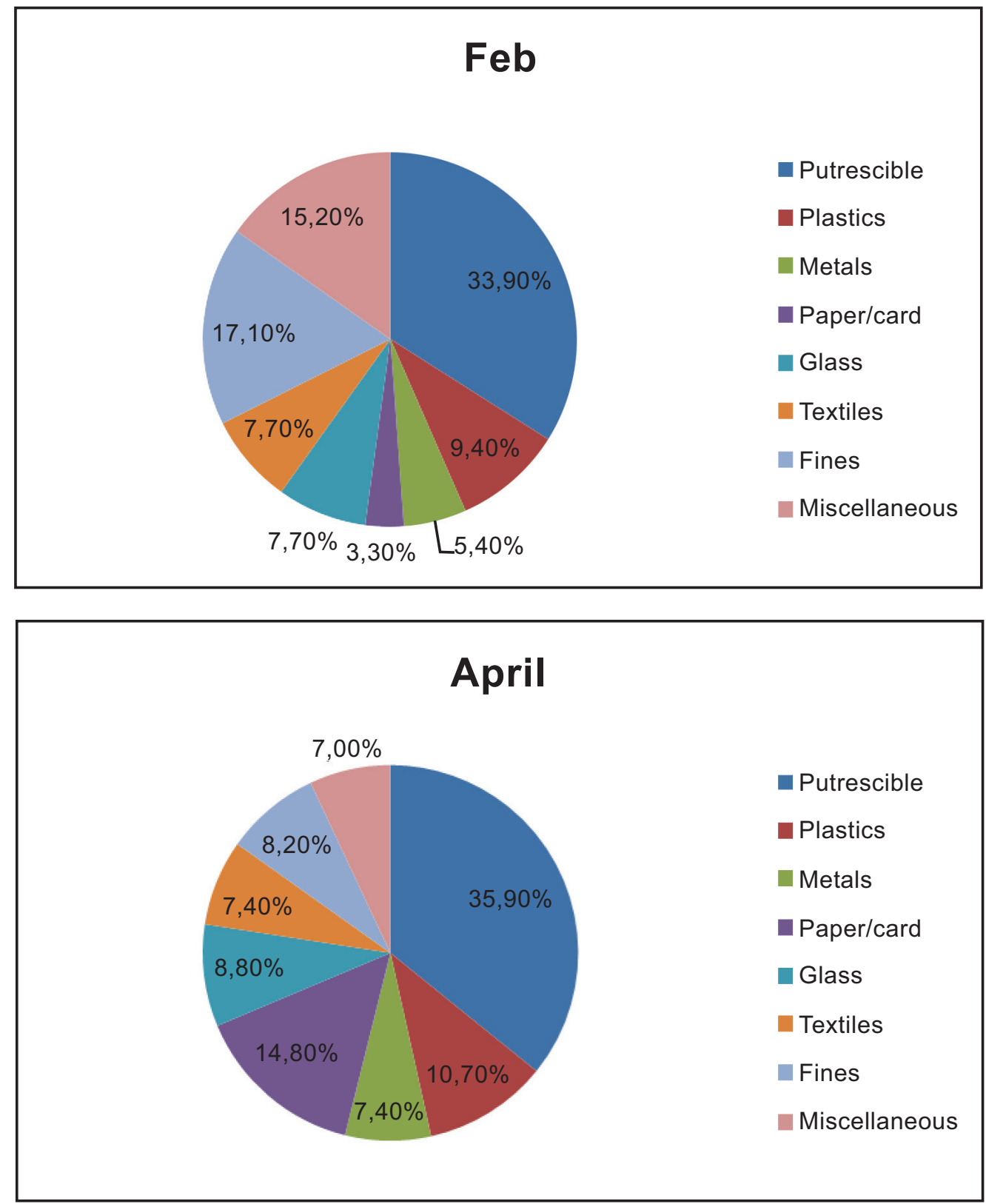

Fig. (3). Composition of household waste in HIRA.

return on capital employed in large scale composting would be too low.

These setbacks can be overcome by the active involvement and participation of all stakeholders in particular the third sector organizations focusing on education and capacity building programs for composting organic waste. This is in line with previous studies [27-31] where it has been indicated that cost effective successes in household waste management operations are driven by the active involvement and participation of different stakeholders. It is on the basis of formulating viable waste management operations for Limbe that a pilot project for training for compost production was designed and implemented, this was facilitated by using formerly waste, and then refurbished computers, to train the local population in best practice [32]. It is recommended that waste planners adopt an approach that encourages local people to empower themselves to develop the capability to run profitable small scale enterprises and so reduce waste and increase resource. In the near future, waste composition studies need also to be carried out on commercial and industrial wastes to help plan reduction programs in this vital area. If we cannot measure we cannot manage, so waste composition studies are vital for future sustainable waste management policy and practice in Limbe.

\section{CONCLUSION}

The Limbe study highlights the fact that household waste generation did not increase with an increase in household size in the LIRA of Limbe. However, household waste 

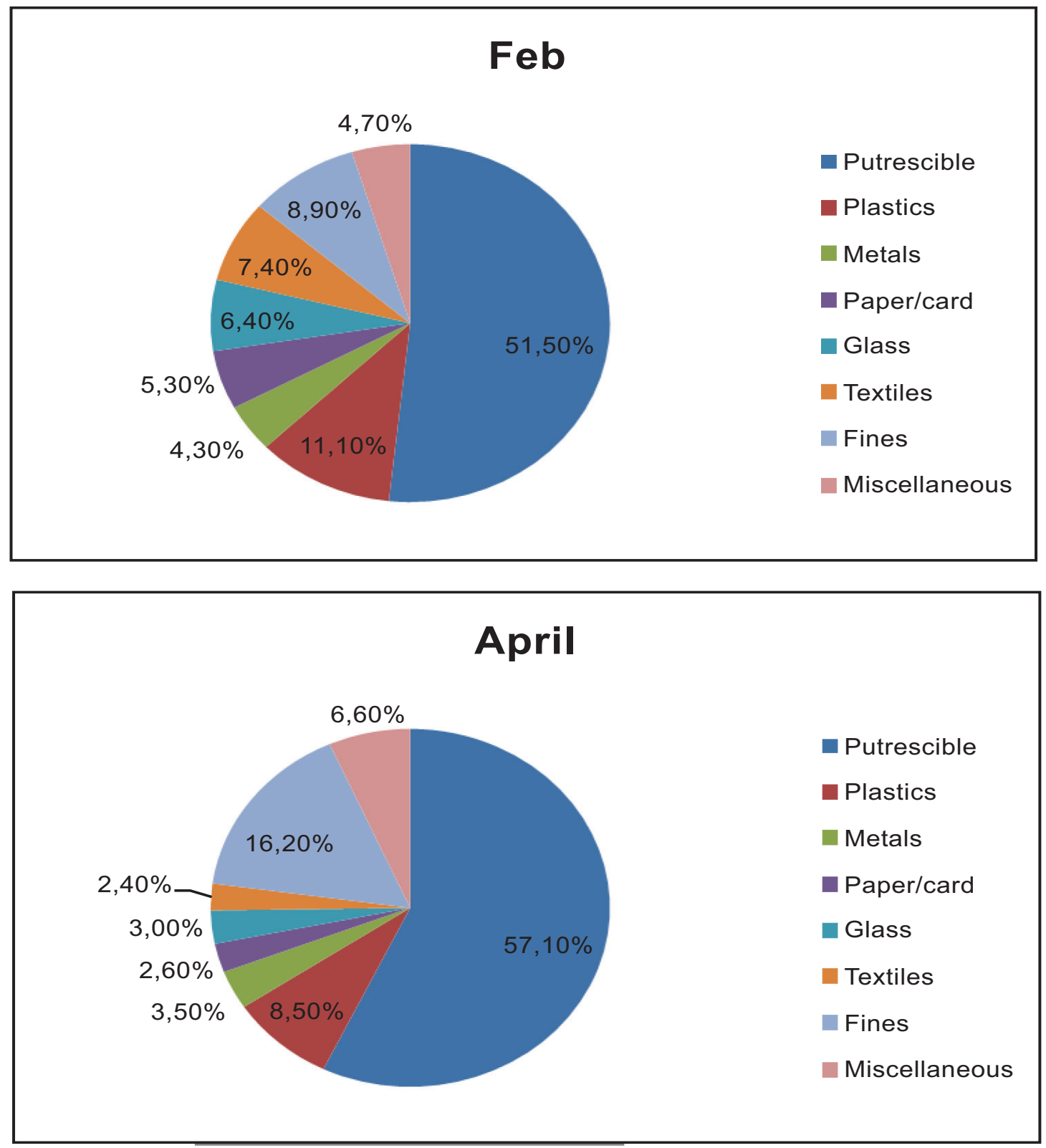

Fig. (4). Composition of household waste in MIRA.

generation in the MIRA and HIRA did show in some cases a weak and in some a strong but significant correlation. The study also found socio geo-demographics and cultural factors responsible for these correlations. The income disparity, culture and lifestyles as well as the level of education were the determining factors of resident's perception to waste as something without value. It is for this reason that a positive change in behavior is possible if the composition, distribution and quantities of the household waste generated are understood. This will ultimately guide municipal authorities on the type of waste management operations adopted. Based on the quantities of the putrescible fractions of the household waste in both the dry and wet seasons in Limbe, this research work recommends small scale composting. However, to overcome the constraints of composting, much has to be done with regards to building capacity for potential composters through education. This will change the mindsets and beliefs of waste as a resource rather than something without value as well as guarantee the production of high quality compost.

\section{CONFLICT OF INTEREST}

The authors confirm that this article content has no conflict of interest.

\section{ACKNOWLEDGEMENTS}

This paper is one of Prof. Paul Phillips free one for 2012 as a member of the editorial board. 

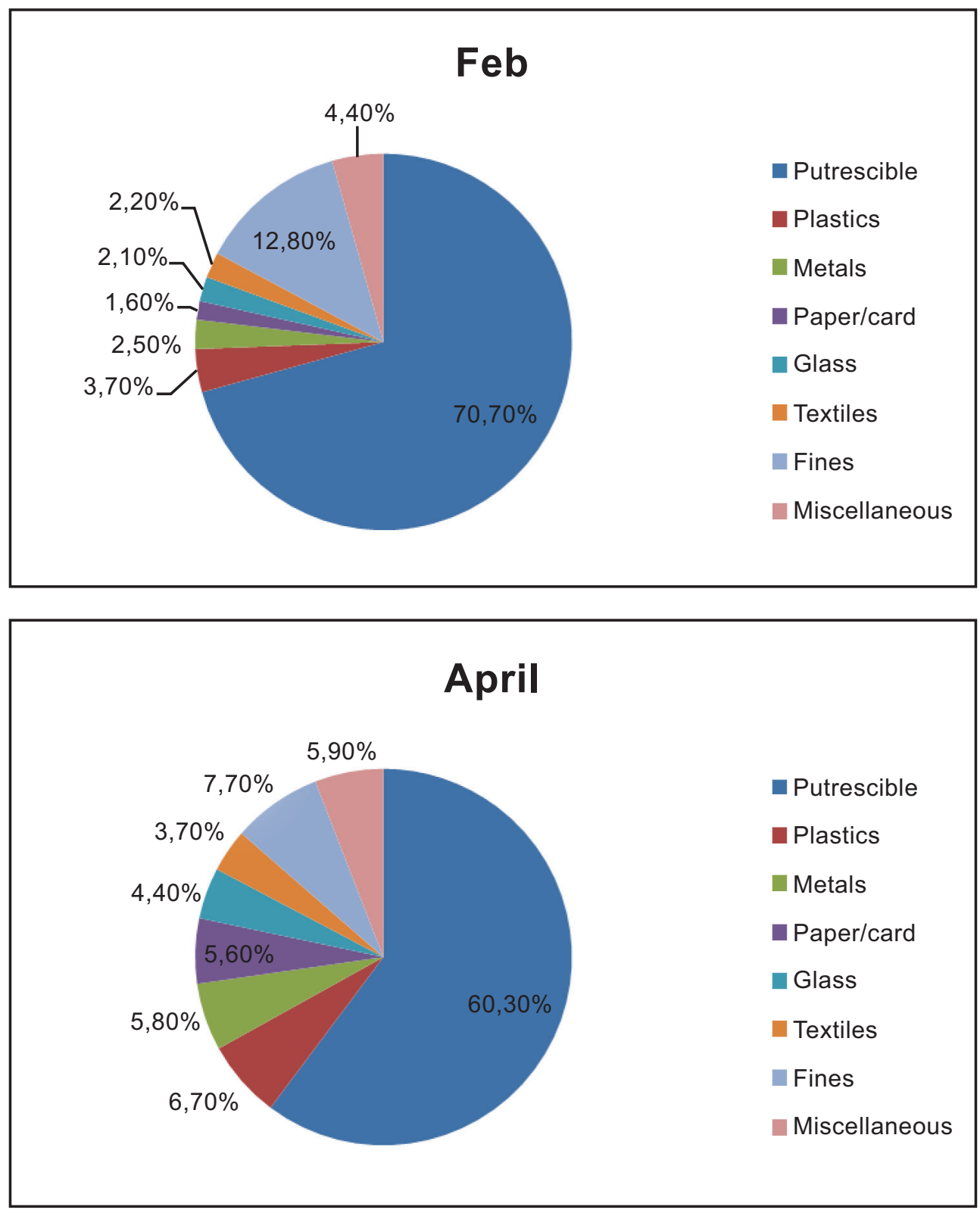

Fig. (5). Composition of household waste in LIRA.

\section{REFERENCES}

[1] G. Tchobanoglous, H. Theisen, and S.A. Vigil, Integrated Solid Waste Management: Engineering Principles and Management Issues. McGraw-Hill: New York, 1993.

[2] S.E. Mbuligwe, "Institutional solid waste management practices in developing countries,: a case study of three academic institutions in Tanzania," In: Resour. Conserv. Recycle, vol. 35, pp. 131-146, 2002.

[3] R. Sha'ato, S.Y.A. Oketunde, F.O. Eneji, I.S.G. Unazi, and S. Agwa, "Survey of solid waste generation and composition in a rapidly growing urban area in Central Nigeria," Waste Manag., vol. 27, no. 3, pp. 352-358, 2006.

[4] African Development Bank, Study on Solid Waste Management Options for Africa: Project Report. African Development Bank: Abidjan, Côte d'Ivoire, 2002.

[5] Department for Environment Food and Rural Affairs, "Waste Composition Analysis: Guidance for Local Authorities. Department for Environment Food and Rural Affairs: London, UK, 2004.
[6] Human Development Report, "Human and income poverty: Developing countries", 2005. [Online]. Available: http://hdr.undp. org/hdr2006/statistics/documents/hpi 1.pdf. [Accessed: $5^{\text {th }}$ May 2008].

[7] S.A. Ahmed, and M. Ali, "Partnerships for solid waste management in developing countries: linking theories to realities," Habitat. Int., vol. 28, no.3, pp. 467-479, 2004.

[8] World Bank, "Upgrading low income settlement country assessment report: Cameroon", 2002. [Online].Available: http://web.mit. edu/urban\%20upgrading/ upgrading/case- examples/Cameroon.htm [Accessed: $30^{\text {th }}$ April 2005].

[9] V.E. Manga, O.T. Forton, and A.D. Read, "Waste management in Cameroon: A new policy perspective?" Resour. Conserv. Recycle, vol. 52, no. 4, pp. 592-600, 2008.

[10] World Bank, World Development Report 1999-2000. World Bank: Washington, D.C, 2000.

[11] D.C. Wilson, A. Whiteman, and A.D. Read, "Strategic planning for solid waste management: An interactive toolkit for developing countries," Waste Manag. World., pp. 55-60, 2003. 
[12] J. Olley, D.C. Wilson, and A.D. Read, "Getting Results",: "Realising the benefits of community participation in strategic planning for municipal waste management," 2006. [Online]. Available: http://d-nb.info/1021685607/34 [Accessed: $22^{\text {nd }}$ April 2008].

[13] National Institute of Statistics, Evolution of National Statistical Systems in Cameroon. National Institute of Statistics: Yaoundé, Cameroon, 2007.

[14] D. Awum, B. Kamanda, and F. Ndongo, "Mainstreaming potentials for sustainable development in Limbe Urban Municipality", 2005. [Online]. Available: http://www.unhabitat.org/offices/roaas/france/ limbe.pdf [Accessed $8^{\text {th }}$ Oct. 2006].

[15] L.O. Mbeng, "The Impact of Public Attitudes and Behavior on the Effective Valorization of Household Organic Waste into Agricultural Compost; Case Study Limbe and Douala, Cameroon", $\mathrm{Ph} . \mathrm{D}$. Thesis, The University of Northampton, Northampton, 2009.

[16] Cameroon National Assembly, "Bill No 597/PJL/AN relating to Environmental Management", Cameroon National Assembly: Yaoundé, 1996.

[17] Waste and Resource Action Programme, "A Quantitative Assessment of the Nature, Scale and Origin of Post Consumer Food Waste Arising. Waste and Resource Action Programme: Banbury, UK, 2006.

[18] K. Parizeau, V. Maclaren, and L. Chanthy, "Waste characterization as an element of waste management planning: Lessons learned from a study in Siem Reap, Cambodia," Resour. Conserv. Recycle, vol. 49 , no. 2, pp. 110-128, 2006

[19] ENTEC UK Ltd and Eunomia Research and Consulting, "Waste Composition Audits 2004/2005 Programme" Cheshire, UK.

[20] World Bank, Country Assessment Report 2000. World Bank: Washington, D.C, 2000

[21] H.A. Abu-qdais, M.F. Hamoda, and J. Newham, "Analysis of residential solid waste at generation sites," Waste Manag. Res., vol. 15, pp. 395-406, 1997.

[22] B. Bolaane, and M. Ali, "Sampling household waste at source: Lessons learnt in Gaborone," Waste Manag., vol. 22, pp. 142-148, 2004.
[23] A. A. Adedibu, "Measuring waste generation in third world cities: a case study of Ilorin, Nigeria," Environ. Monit. Assess., vol. 10, pp. 89-103, 1988.

[24] Japan International Cooperation Agency, Supporting Capacity Development in Solid Waste Management in Developing Countries- towards improving Solid Waste Management Capacity of Entire Societies, Japan International Cooperation Agency: Tokyo, Japan, 2005.

[25] S.E. Mbuligwe, "Institutional solid waste management practices in developing countries: a case study of three academic institutions in Tanzania," Resour. Conserv. Recycle, vol. 35, pp. 131-146, 2002.

[26] L.O. Mbeng, P.S. Phillips, and R. Fairweather, "Managing hazardous components in household waste in developing countries: lessons learnt from community composting in Cameroon," J. Solid Waste Tech. Manag., vol. 36, no. 3, pp. 153-163, 2010.

[27] N. Marchettini, R. Ridolfi, and M. Rustici, "An environmental analysis for comparing waste management," Waste Manag., vol. 27, no. 4, pp. 562-571, 2006.

[28] R.R. Mohan, R.J. Spiby, G.S. Leonardi, A. Robins, and S. Jefferis, "Sustainable waste management in the UK: The public health role," Pub. Health., vol. 120, pp. 908-914, 2006.

[29] J.M. Mosler, S. Drescher, Zurbrugg, T.C. Rodriguez, and O.G. Miranda, "Formulating waste management strategies based on waste management practices of households in Santiago de Cuba," Habitat. Int.,vol. 10, no. 4, pp. 849-862, 2006.

[30] G. Schleenstein, "Gestion de Residuos Solidos Urbanos en Cuba con un Enfoque al Municipio Minero de Moa. Programa ASA 2002 de la Carl-Duisberg-Gesellschaft”, 2002.

[31] K. Joseph, "Stakeholder participation for sustainable waste management," Habitat. Int.,vol. 30, pp. 863-871, 2006.

[32] M. Bates, L.O. Mbeng, and P.S. Phillips, "Managing e-waste- A reuse strategy for UK computers to facilitate developments in third sector organization composting in Cameroon," J. Solid Waste Tech. Manag., vol. 34, no. 4, pp. 204-212, 2008.

(C) Mbeng et al.; Licensee Bentham Open.

This is an open access article licensed under the terms of the Creative Commons Attribution Non-Commercial License (http://creativecommons.org/licenses/by$\mathrm{nc} / 3.0 /$ ) which permits unrestricted, non-commercial use, distribution and reproduction in any medium, provided the work is properly cited. 